\title{
Study of Pumping Capacity of Pitched Blade Impellers
}

\author{
I. Fořt, T. Jirout, R. Sperling, S. Jambere, F. Rieger
}

A study was made of the pumping capacity of pitched blade impellers in a cylindrical pilot plant vessel with four standard radial baffles at the wall under a turbulent regime of flow. The pumping capacity was calculated from the radial profile of the axial flow, under the assumption of axial symmetry of the discharge flow. The mean velocity was measured using laser Doppler anemometry in a transparent vessel of diameter $T=400 \mathrm{~mm}$, provided with a standard dished bottom. Three and six blade pitched blade impellers (the pitch angle varied within the interval $\left.\alpha \in\left\langle 24^{\circ} ; 4^{\circ}\right\rangle\right)$ of impeller/vessel diameter ratio $D / T=0.36$, as well as a three blade pitched blade impeller with folded blades of the same diameter, were tested. The calculated results were compared with the results of experiments mentioned in the literature, above all in cylindrical vessels with a flat bottom. Both arrangements of the agitated system were described by the impeller energetic efficiency, i.e, a criterion including in dimensionless form both the impeller energy consumption (impeller power input) and the impeller pumping effect (impeller pumping capacity). It follows from the results obtained with various geometrical configurations that the energetic efficiency of pitched blade impellers is significantly lower for configurations suitable for mixing solid-liquid suspensions (low impeller off bottom clearances) than for blending miscible liquids in mixing (higher impeller off bottom clearances).

Keywords: pitched blade impeller, impeller pumping capacity, turbulent flow, laser Doppler anemometer, impeller energetic efficiency.

\section{Introduction}

The pumping capacity of a pitched blade impeller (PBT) is defined [1] as the amount of liquid leaving the rotor region of the impeller, i.e., the cylindrical volume circumscribed by the rotating impeller blades, per unit time. This quantity is an important process characteristic of the PBT and plays an important role when calculating the blending or homogenization time of miscible liquids in mixing $[2,3]$, in the design of continuous-flow stirred reactors [4] and in calculating the process characteristics of solid-liquid suspensions [5], i.e. the impeller frequency for just off bottom suspension.

The pumping capacity of a PBT can be measured by the indirect "flow follower" (indicating particle) method [1] and calculated from the measured mean time of liquid primary circulation, or calculated $[3,5,6]$ from the known radial profile of the axial component of the mean velocity in the impeller discharge stream leaving the impeller rotor region by means of integration over the circular cross section of the impeller rotor region.

The pumping capacity of the PBT $Q_{\mathrm{p}}$ can be expressed in dimensionless form as the impeller flow rate number $[1,2]$

$$
N_{Q_{\mathrm{p}}}=Q_{\mathrm{p}} / n D^{3},
$$

where $n$ is the frequency of the impeller revolution and $D$ is its diameter. Quantity $N_{Q_{\mathrm{p}}}$ does not depend on the Reynolds number of the impeller when this quantity exceeds ten thousand $[1,3,6]$. For impeller power input $P$ the Power number has been introduced

$$
P o=P / \rho n^{3} D^{5} \text {, }
$$

where $\rho$ is the density of the agitated liquid. This quantity is also independent of the impeller Reynolds number when it exceeds ten thousand. A combination of the dimensionless quantities $N_{Q_{\mathrm{p}}}$ and $P o$ gives the so called hydraulic efficiency of the impeller $[2,7]$ defined as

$$
E_{\mathrm{p}}=\frac{N_{Q_{\mathrm{p}}}^{3}}{P_{0}}\left(\frac{D}{T}\right)^{4},
$$

where $T$ is the diameter of the vessel.
The higher the quantity $E_{\mathrm{p}}$, the greater the ability to convert impeller energy consumption into its pumping effect.

This study deals with an analysis of the pumping and energetic efficiency of various pitched blade impellers under two main geometrical conditions: conditions convenient for solid-liquid suspensions operations and conditions convenient for blending miscible liquids. The PBT pumping capacity will be calculated from the radial profile of the axial component of the mean velocity in the impeller discharge stream leaving the impeller rotor region. The velocity profile will be determined by laser Doppler anemometry.

\section{Experimental}

Experiments were carried out in a pilot plant cylindrical vessel with adished bottom [9] - see Fig. 1. The vessel had

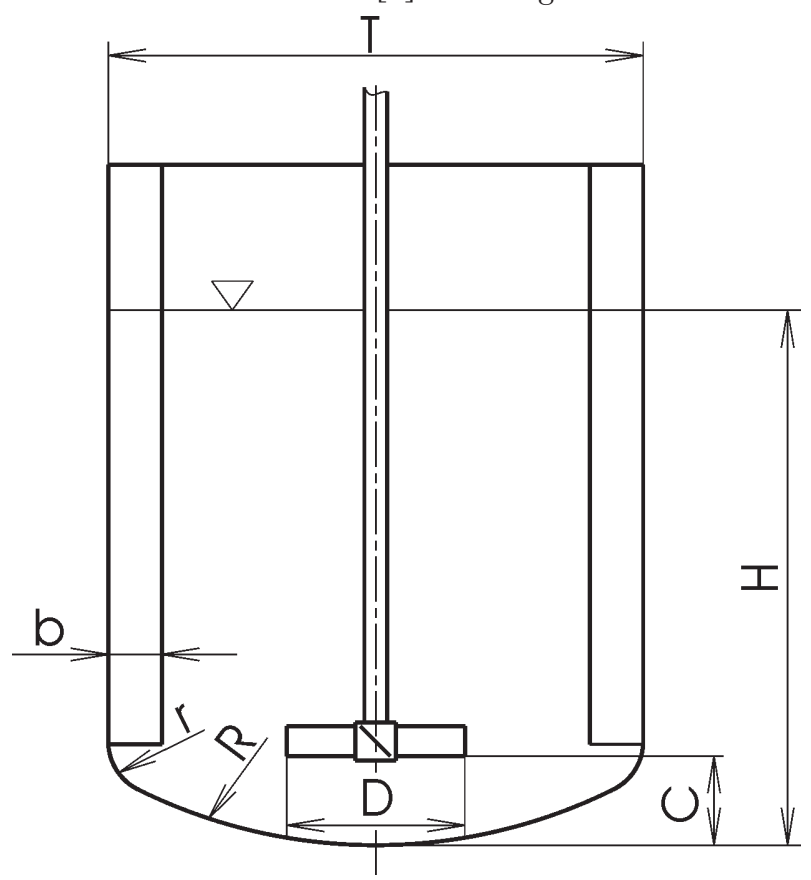

Fig. 1: Layout of test rig with dished bottom $(H / T=0.36, C / D=$ $=0.5, b / T=0.1, R / T=1, r / T=0.1)$

Czech Technical University Publishing House 


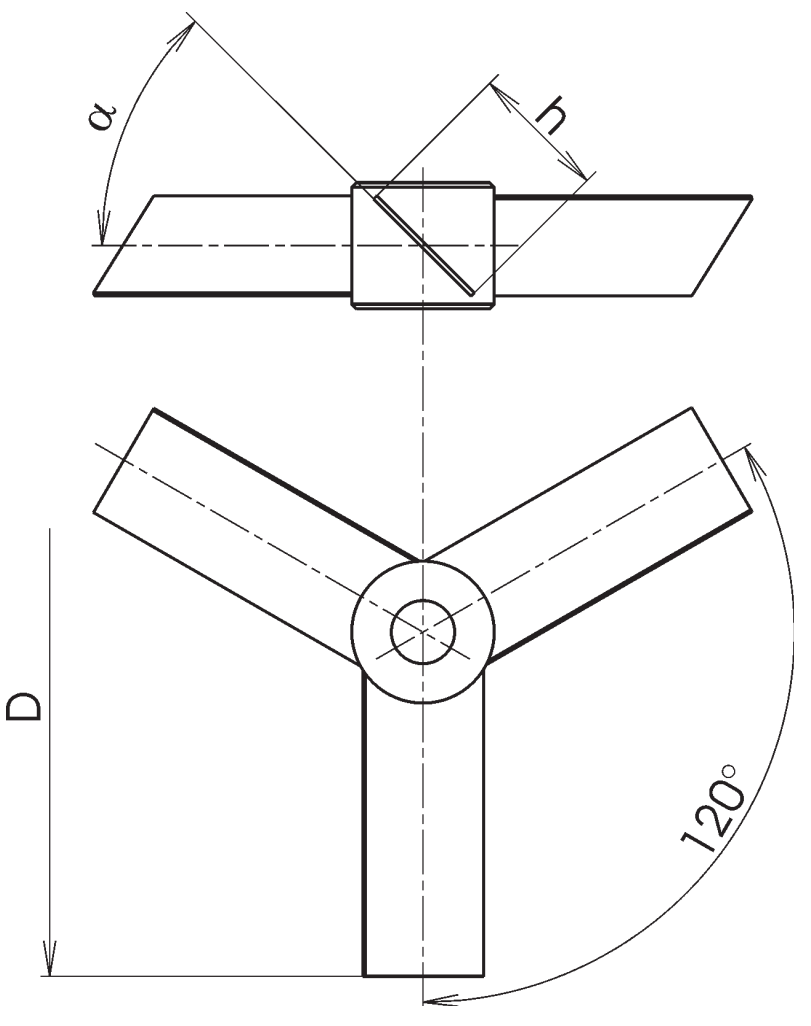

al
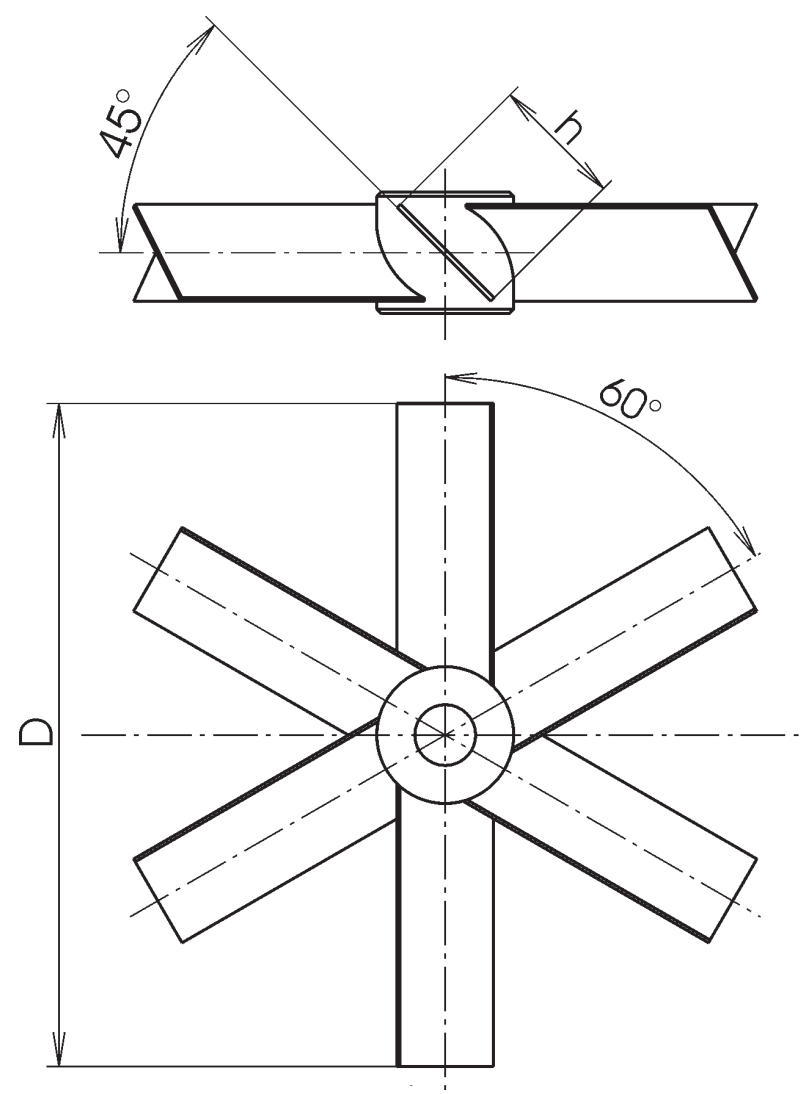

$\mathrm{b} /$

Fig. 2: Sketch of pitched blade impellers with three or six blades - Czech Standard CVS $691020\left(\mathrm{a} / n_{\mathrm{B}}=3: \alpha=24^{\circ}, 35^{\circ}, 45^{\circ}, \mathrm{b} / n_{\mathrm{B}}=6\right.$ : $\alpha=45^{\circ}, h / D=0.2$ )

diameter $T=400 \mathrm{~mm}$ and was equipped with four equally spaced radial baffles mounted at the wall. It was filled with water at a temperature of $20{ }^{\circ} \mathrm{C}$ to a height of $H=T$. The frequency of revolution of the impeller was measured by means of a photoelectric cell with an accuracy $\pm 1 \mathrm{rev} / \mathrm{min}$.

Figs. 2 and 3 show geometrical sketches of the pitched blade impellers used in this study. Two types of impellers were investigated: simple PBTs (see Fig. 2) and a PBT with folded blades (see Fig. 3). Both types of impellers had a

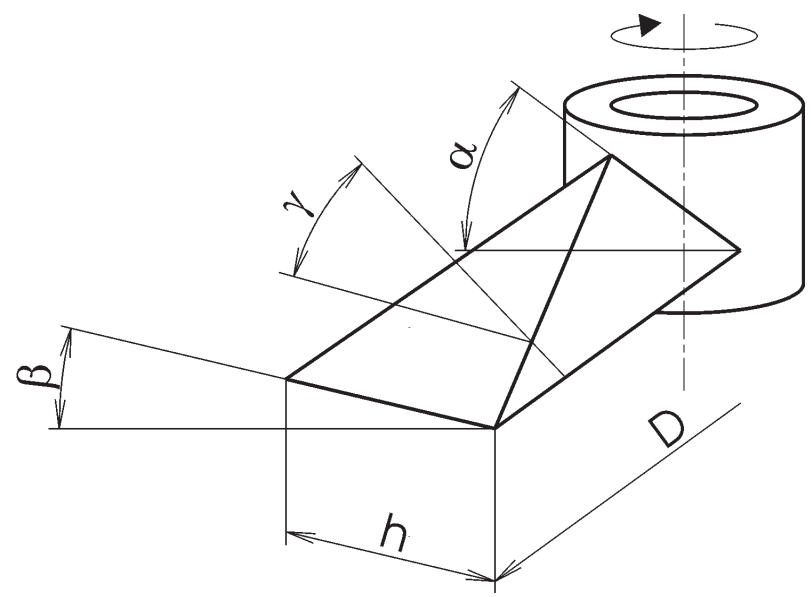

Fig. 3: Sketch of a pitched blade impeller with folded blades Czech Standard CVS $691010\left(n_{\mathrm{B}}=3, s / D=1.5, \alpha=67^{\circ}\right.$, $\beta=25^{\circ}, \gamma=48^{\circ}, h / D=0.2$ ) relative diameter $D / T=0.36$ and relative off bottom clearance $C / D=0.5$. The off bottom clearance was measured from the centre of the dished bottom to the lower edge of the impeller using a ruler, with a precision of $\pm 1 \mathrm{~mm}$. The error in measuring the blade angle of the PBTs can be considered as $\pm 0.5^{\circ}$. All the PBTs rotated in such a way that they pumped liquid downwards towards the bottom.

The mean velocity field in the impeller discharge flow just below the impeller rotor region was measured with a laser Doppler anemometer (LDA). A DANTEC 55X two component modular series LDA and its associated BSA data processor, connected with a PC, was used for the experiments. The LDA was operated in a forward scatter mode (see Fig. 4). The laser (5-W Ar ion, manufactured by Spectra Physics,

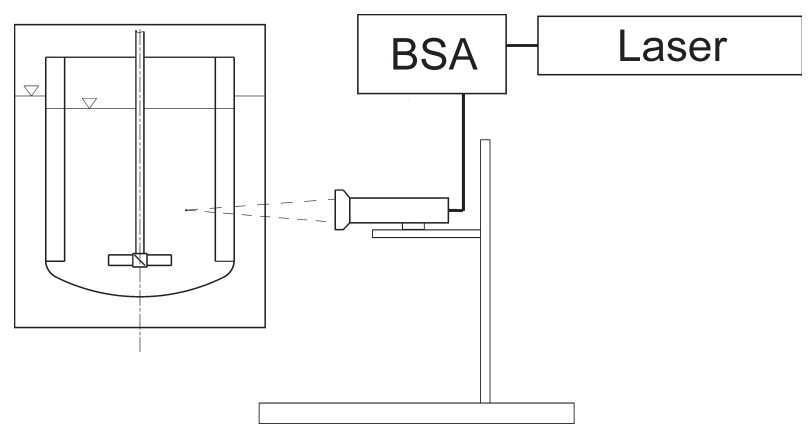

Fig. 4: Layout of a laser Doppler anemometer with forward scatter mode 
USA) and optics were mounted on a bench which has a two-dimensional traversing mechanism. To identify the flow reversals correctly, a frequency shift was given to one of the beams by means of a Bragg cell with electronic downmixing. Two components of the local velocity were measured simultaneously, with positioning accuracy $\pm 0.1 \mathrm{~mm}$. The sample size was set at 20,000 items for each velocity measurement, and the mean time (averaged) value from all the samples was calculated.

\section{Results and discussion}

The impeller pumping capacity $Q_{p}$ was calculated from the experimentally determined radial profiles of the axial component of the mean velocity in the impeller discharge stream leaving the impeller rotor region $w_{\mathrm{ax}}=w_{\mathrm{ax}}(r)$. The local value of the mean velocity corresponds to the ensemble average value over the circle of radius $r$ determined by LDA. Assuming axial symmetry of the impeller discharge stream, the impeller pumping capacity can be calculated from the equation

$$
Q_{\mathrm{p}}=2 p \int_{0}^{D / 2} \overline{w_{\mathrm{ax}}}(r) \mathrm{d} r .
$$

Fig. 5 depicts the measured radial profiles of the axial components of the mean velocity in the impeller discharge flow related to the impeller tip speed

$$
W_{a x}=\frac{\overline{w_{\mathrm{ax}}}}{\pi D n},
$$

at various impeller frequencies of revolution. This figure provides quite a good illustration of the independence of the dimensionless quantity $w_{\mathrm{ax}}$ from the frequency of revolution of the impeller corresponding to the fully turbulent regime of agitated liquid. Dimensionless radial coordinate $2 r / T$ defines the velocity profile in the axial discharge flow [1]. In the vicinity of the impeller hub $(2 r / T \in\langle 0 ; 0,1\rangle)$ the liquid velocity amounts to a zero value, then it increases in the region of the

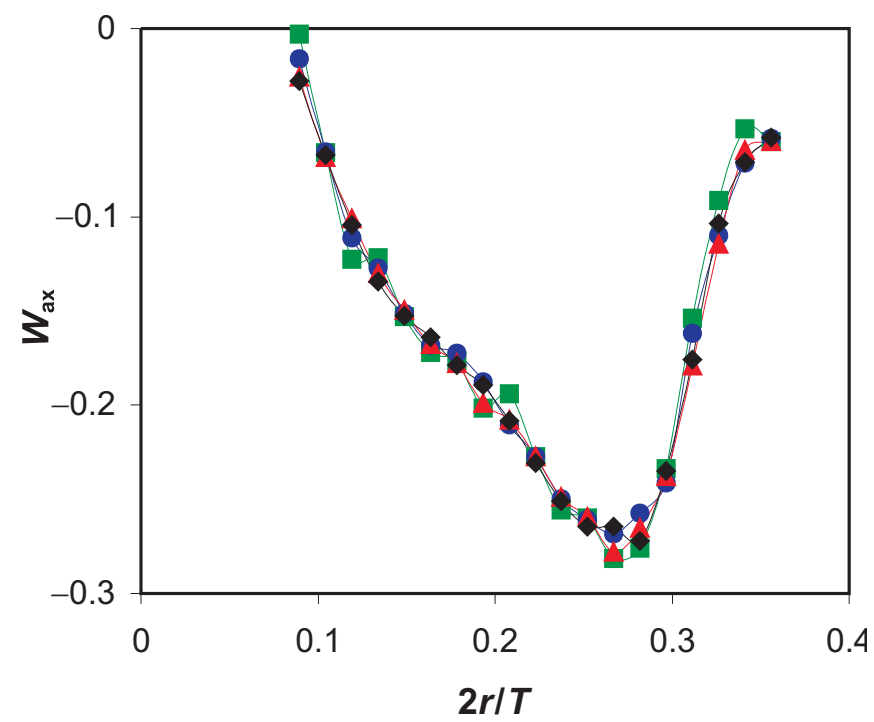

Fig. 5: Radial distribution of the axial component of the dimensionless mean velocity in a liquid leaving the rotor region of a pitched blade impeller $-n_{\mathrm{B}}=3, \alpha=24^{\circ}\left(n\left[\mathrm{~min}^{-1}\right]-\right.$ point: $162-\bullet, 210-\bullet, 261-\boldsymbol{\Delta}, 310-$
Rankin forced vortex and, finally, it decreases in the region of the trailing vortices behind the impeller blades [1].

Table 1 consists of the above mentioned results of calculations for all the impellers tested (the value of criterion $N_{Q_{\mathrm{p}}}$ is the arithmetic mean value from the values of $Q_{\mathrm{p}}$ (or $N_{Q_{\mathrm{p}}}$ ), calculated according to formulas (1) and (4) from the experimental velocity data) and further values of the Power number $P$ o calculated from Eq. 2. The impeller power input was also determined experimentally by means of a strain gauge torquemeter mounted on the impeller shaft. Finally, the value of the impeller hydraulic efficiency was calculated from Eq. (3) and was included in Table 1.

Table 1: Dimensionless pumping and energetic characteristics of pitched blade impellers in a baffled system with a dished bottom $(H / T=1, D / T=0.36, C / D=0.5)$

\begin{tabular}{|c|c|c|c|c|}
\hline$n_{\mathrm{B}}$ & $\alpha$ & $N_{Q_{\mathrm{p}}}$ & $P o$ & $E_{\mathrm{p}}$ \\
\hline$[-]$ & {$\left[{ }^{\circ}\right]$} & {$[-]$} & {$[-]$} & {$[-]$} \\
\hline 3 & 24 & 0.41 & 0.37 & 0.00312 \\
\hline 3 & 35 & 0.51 & 0.79 & 0.00282 \\
\hline 3 & 45 & 0.56 & 1.27 & 0.00232 \\
\hline 6 & 45 & 0.65 & 1.81 & 0.00255 \\
\hline
\end{tabular}

Table 2 consists of the dimensionless pumping and energetic characteristics of PBTs in a baffled system with a flat

Table 2: Dimensionless pumping and energetic characteristics of pitched blade impellers in a baffled system with a flat bottom

I. Results of $\mathrm{Wu}$ and co-workers [5] $(H / T=1, D / T=0.41$, $C / D=0.815)$

\begin{tabular}{|c|c|c|c|c|}
\hline$n_{\mathrm{B}}$ & $\alpha$ & $N_{Q_{\mathrm{p}}}$ & $P_{0}$ & $E_{\mathrm{p}}$ \\
\hline$[-]$ & {$\left[{ }^{\circ}\right]$} & {$[-]$} & {$[-]$} & {$[-]$} \\
\hline 4 & 20 & 0.43 & 0.27 & 0.00832 \\
\hline 4 & 25 & 0.53 & 0.37 & 0.01137 \\
\hline 4 & 30 & 0.58 & 0.56 & 0.00951 \\
\hline 4 & 35 & 0.65 & 0.73 & 0.01063 \\
\hline 4 & 40 & 0.72 & 0.97 & 0.01087 \\
\hline 4 & 45 & 0.76 & 1.22 & 0.1016 \\
\hline 2 & 30 & 0.49 & 0.45 & 0.00739 \\
\hline 3 & 30 & 0.54 & 0.53 & 0.00840 \\
\hline 5 & 30 & 0.60 & 0.69 & 0.00847 \\
\hline 6 & 30 & 0.61 & 0.72 & 0.00891 \\
\hline
\end{tabular}

II. Results of Fořt and Medek [7] $(D / T=0.33, C / D=0.1)$

\begin{tabular}{|c|c|c|c|}
\hline$n_{\mathrm{B}}$ & $\alpha$ & $E_{\mathrm{p}}$ & Note \\
\hline$[-]$ & {$\left[{ }^{\circ}\right]$} & {$[-]$} & \\
\hline $2-6$ & $25-60$ & 0.00742 & $\begin{array}{c}\text { Impeller with } \\
\text { folded blades } \\
\text { (see Fig. 3) }\end{array}$ \\
\hline $2-6$ & $s / D=1.0-1.25$ & 0.00864 & \\
\hline
\end{tabular}


bottom found in the literature under conditions of higher off bottom impeller clearance than those set up in our study.

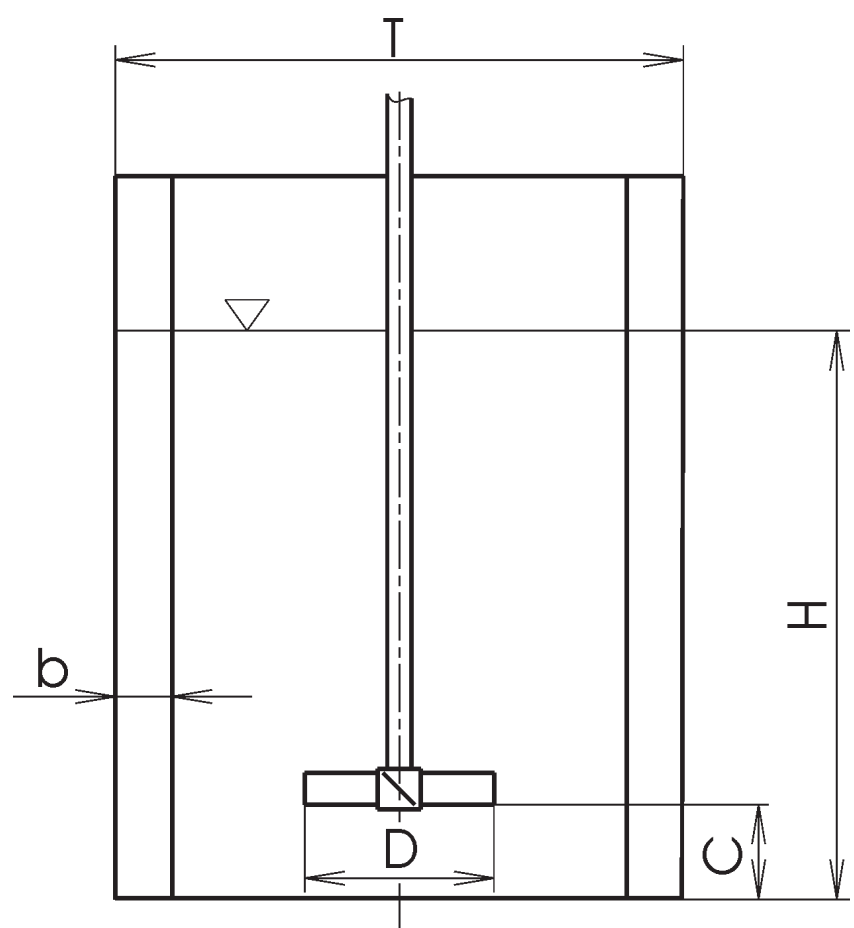

Fig. 6: Layout of a cylindrical agitated flat bottomed system $(H / T=1, D / T=1 / 3, C / D=0.5$ or $1, b / T=1)$

The flow rate criterion $N_{Q_{\mathrm{p}}}$ and the Power number $P_{0}$ were correlated in the literature on the basis of many experiments carried out for pitched blade impellers in a baffled flat bottomed cylindrical pilot plant agitated system (see Fig. 6) under a turbulent regime of an agitated liquid. Medek [7] published a correlation

$P_{0}=1.507 n_{\mathrm{B}}^{0.701}(C / D)^{-0.165}(T / D)^{-0.365}(H / T)^{0.140}(\sin \alpha)^{2.077}$

while Medek and Fořt [1] published

$N_{Q_{\mathrm{p}}}=0.745 n_{\mathrm{B}}^{0.233}(C / D)^{0.254}(T / D)^{0.023}(H / T)^{0.251}(\sin \alpha)^{0.468} .(7)$

The intervals of the validity of the two correlations are as follows:

$n_{\mathrm{B}} \in\langle 2 ; 8\rangle, C / D \in\langle 0.2 ; 1.0\rangle, T / D \in\langle 2.45 ; 5.93\rangle, H / T \in\langle 0.55 ; 1.0\rangle$, $\alpha \in\left\langle 15^{\circ} ; 60^{\circ}\right\rangle, 4$ baffles $(b / T=0.1), \operatorname{Re}_{\mathrm{M}}>1.0 \cdot 10^{4}$.

Taking the data of Kresta and Wood [6] and comparing it with correlation (7) we can write the relation

$N_{Q_{\mathrm{p}}} \sim(C / D)^{0.244}, D / T=1 / 3, H / T=1, C / D \in\langle 0.165 ; 0.875\rangle$.

The exponent at the geometrical simplex C/D mentioned in Eq. (8) following from the data of Kresta and Wood corresponds fairly well to the exponent at the same simplex in Eq. (7). Similarly, we can compare relation [5]

$N_{Q_{\mathrm{p}}} \sim n_{\mathrm{B}}^{0.215}, D / T=0.41, H / T=1, C / D=0.813, n_{\mathrm{B}} \in\langle 2 ; 6\rangle$

with the corresponding relation within Eq. (7) and, again, the two exponents for the equivalent quantity $\left(n_{\mathrm{B}}\right)$ agree fairly well.

(C) Czech Technical University Publishing House
A combination of Eqs. (6) and (7) according to the definition of the hydraulic efficiency of the impellers (Eq. 3) gives for the squared configuration of the agitated system $(H / T=1)$ $E_{\mathrm{p}}=0.274 n_{\mathrm{B}}^{-0.008}(C / D)^{0.597}(D / T)^{3.566}(\sin \alpha)^{-0.673}$

The exponent for the number of impeller blades in Eq. (8) can be neglected with respect to its statistical significance. Table 3 shows the values of impeller hydraulic efficiency

Table 3: Hydraulic efficiency of a pitched blade impeller calculated from data correlation (10) in a system with a flat bottom $(H / T=1, D / T=0.36)$

\begin{tabular}{|c|c|c|c|}
\hline$C / D$ & $n_{\mathrm{B}}$ & $\alpha$ & $E_{\mathrm{p}}$ \\
\hline$[-]$ & {$[-]$} & {$\left[{ }^{\circ}\right]$} & {$[-]$} \\
\hline 0.5 & 3 & 24 & 0.00768 \\
\hline 0.5 & 3 & 35 & 0.00689 \\
\hline 0.5 & 3 & 45 & 0.00598 \\
\hline 0.5 & 6 & 45 & 0.00598 \\
\hline 1.0 & 3 & 24 & 0.01200 \\
\hline 1.0 & 3 & 35 & 0.01042 \\
\hline 1.0 & 3 & 45 & 0.009045 \\
\hline 1.0 & 6 & 45 & 0.009045 \\
\hline
\end{tabular}

$E_{\mathrm{p}}$ under various geometrical conditions calculated from Eq. (10). Comparing the values of the impeller hydraulic efficiency in Tables 1-3, we can consider as important the influence of the impeller off bottom clearance $C / D$ and, also, probably, the shape of the bottom. The curved shape of the bottom and the shorter distance between the impeller and the bottom, both important geometric features suitable for solid liquid suspension during mixing, reduce the ability of the impeller to convert its power input into its pumping efficiency. On the other hand, when there is a longer distance between the impeller and the bottom, i.e., under conditions suitable for blending of miscible liquids during mixing [3], the hydraulic efficiency of the pitched blade impeller exhibits fairly high values. A pitched blade impeller with folded blades (see Fig. 3) corresponds quite well to its original design purpose [7], i.e., to replace the shape of the complex surface of the marine propeller by the simple and well defined shape of the folded blade of a pitched blade impeller when its hydraulic efficiency is the same as the value of this quantity for a marine propeller.

\section{Conclusions}

The pumping capacity of pitched blade impellers depends significantly under a turbulent regime of flow on the geometry of agitated system, i.e., on the shape of the bottom, the impeller off bottom clearance, and the impeller/vessel diameter ratio.

The impeller hydraulic efficiency exhibits higher values for impeller off bottom clearance equal to the impeller diameter than for half of this distance, when interference between the bottom and the impeller takes place. This 
phenomenon is more apparent when the dished bottom of the cylindrical vessel is introduced.

\section{List of Symbols}

$b \quad$ baffle width, $\mathrm{m}$

C off bottom impeller clearance, $\mathrm{m}$

$D$ impeller diameter, $\mathrm{m}$

$E_{\mathrm{p}} \quad$ impeller hydraulic efficiency

$H$ height of liquid from bottom of vessel, $\mathrm{m}$

$h \quad$ width of impeller blade, $\mathrm{m}$

$N_{Q_{\mathrm{p}}}$ flow rate number

$n$ impeller frequency of revolution, $\mathrm{s}^{-1}$

$n_{\mathrm{B}} \quad$ number on impeller blades

$P \quad$ impeller power input, $\mathrm{W}$

$P o \quad$ power number

$Q_{\mathrm{p}} \quad$ impeller pumping capacity, $\mathrm{m}^{3} \mathrm{~s}^{-1}$

$\mathrm{Re}_{\mathrm{M}} \quad$ Reynolds number

$R \quad$ radius of dished bottom, $\mathrm{r}$

$r \quad$ radius of round corners of dished bottom, $m$

$r \quad$ radius, $\mathrm{m}$

$s \quad$ pitch, $\mathrm{m}$

$T$ vessel diameter, $m$

$W_{\text {ax }}$ dimensionless axial component of the liquid mean velocity

$\overline{w_{\mathrm{ax}}}$ axial component of the liquid mean velocity, $\mathrm{m} \mathrm{s}^{-1}$

$\alpha \quad$ pitch angle of blade, ${ }^{\circ}$

$\beta \quad$ pitch angle of blade, ${ }^{\circ}$

$\gamma \quad$ angle, ${ }^{\circ}$

$\rho \quad$ density of agitated liquid, $\mathrm{kg} \mathrm{m}^{-3}$

\section{Acknowledgment}

This research was supported by research project of the Ministry of Education of the Czech Republic No. JO4/98: 212200008.

\section{REFERENCES}

[1] Medek, J., Fořt, I.: Pumping effect of impellers with flat inclined blades. Collect. Czech. Chem. Commun., Vol. 44, 1979, p. 3077 - 3089.

[2] Nienow, A. W.: On impeller circulation and mixing effectiveness in the turbulent flow regime. Chem. Eng. Sci., 1997, Vol. 22, No. 15, p. 2557-2565.
[3] Patwardhan, A. W., Joshi, J. B.: Relation between flow pattern and blending in stirred tanks. Ind. Eng. Chem. Res., 1999, Vol. 38, p. 3131-3143.

[4] Mavros, P., Xuereb, C., Fořt, I., Bertrand, J.: Investigation of flow patterns in continuous - flow stirred vessel by laser Doppler velocimetry. Can. J. Chem. Eng., 2002 in press.

[5] Wu, J., Zhu, Y., Pullum, L.: The effect of impeller pumping and fluid rheology on solid suspension in a stirred vessel. Can. J. Eng., 2001, Vol. 79, p. 177-186.

[6] Kresta, S., Wood, P.: The flow field produced by a $45^{\circ}$ pitched blade turbine: Changes in the circulation pattern due to off bottom clearance. Can. J. Chem. Eng., 1993, Vol. 71, p. 42-53.

[7] Fořt, I., Medek, J.: Hydraulic and energetic efficiency of impellers with inclined blades. Proceedings of the $6^{\text {th }}$ European Conference on Mixing, Pavia (Italy), May 1988, p. 51-56.

[8] Medek, J.: Power characteristics of agitators with flat inclined blades. Int. Eng. Chem. 1980, Vol. 20, No. 4, p. 664-672.

[9] Deeply dished bottoms for pressure vessels. Czech Standard ČSN 425815, Prague 1980.

Doc. Ing. Ivan Fořt, DrSc.

phone: +420224352713

Fax: +420224310292

e-mail: fort@fsid.cvut.cz

Ing. Tomáš Jirout

Prof. Ing. František Rieger, DrSc.

Dept. of Process Engineering

Czech Technical University in Prague

Faculty of Mechanical Engineering

Technická 4

16607 Praha 6, Czech Republic

Prof. Dr.-Ing. Reinhard Sperling e-mail: reinhard.sperling@lbv.hs-anhalt.de

Ing. Solomon Jambere

Dept. of Chemical Engineering

Anhalt University of Appl. Sciences

Hochschule Anhalt (FH)

Bernburger Str. 52-57

06366 Koethen, Germany 